\title{
Knowledge, perception and screening of local dye workers regarding urinary bladder cancer in Ghana
}

\author{
Babatunde M. Duduyemi ${ }^{*} \mathbb{0}$, Divine Lardey Agyemang ${ }^{2}$, Ernest Adankwah², Hannah Nyarko ${ }^{1}$ \\ and Derrick Andoh'
}

\begin{abstract}
Background: Cancer is the leading cause of death with 7.6 million deaths worldwide annually. About 19\% of bladder cancer cases are attributed to environmental and occupational factors. The knowledge of any disease is very vital in the control or prevention of such disease. This study examined the knowledge and perception of urinary bladder cancer among 104 local dye workers in Ghana (Kumasi, Koforidua and Somanya).

Methods: A well-structured questionnaire was used to measure participants' knowledge and perception towards bladder cancer. Forty out of the 104 participants were recruited to provide their urine samples for cytomorphological study. Thin smears were prepared and stained with Papanicolaou stain. Respondents were selected based on clinical history and working experience.

Result: The response rate to the questionnaires was 100\% of the 104 respondents interviewed. The respondents had a mean age of 26 years. Overall, about $10 \%$ of the respondents in this study had good knowledge levels on bladder cancer and 16\% had good perception of the disease. There was a significant correlation between knowledge and educational level of the participants $(p<0.001)$. Report of the cytomorphological study indicates that none of the samples of the participants screened had cancerous cells.
\end{abstract}

Conclusion: The findings suggest that level of knowledge about bladder cancer among local dye workers in this study was low, while their level of perception was just above average.

Keywords: Bladder cancer, Dye workers, Knowledge, Perception, Screening

\section{Background}

Cancer is the leading cause of death, with an annual death of 7.6 million worldwide. About $19 \%$ of cancers are attributed to environmental and occupational factors [1, 2].

Bladder cancer is the fourth most common internal malignancy in American men and also one of the 10 deadliest cancers [3]. However, early diagnosis can nip the disease in the bud. The American Cancer Society

\footnotetext{
*Correspondence: tundeduduyemi@gmail.com

1 Department of Pathology, Kwame Nkrumah University of Science and Technology, Kumasi, Ghana

Full list of author information is available at the end of the article
}

estimated that 74,000 new cases of bladder cancer will be diagnosed in the USA in 2015 [4]. In 2008, the American cancer society estimated the numbers of new cases and deaths of bladder cancer in Africa to be 11,400 [5]. In 2018, the pooled incidence of bladder cancer in Africa was 7.0 (5.8-8.3) per 100,000 population in men and $1.8(1.2-2.6)$ per 100,000 in women [6]. Statistically, men are up to four times as likely as women to get bladder cancer, although people working around hazardous chemicals would be more likely to get bladder cancer irrespective of sex $[5,7]$. These include hairdressers, machinists, metal workers and truck drivers, with people working in rubber, textiles, paint and leather industries being at a higher 
risk. Unlimited exposure to chemicals containing aromatic amines, such as benzidine and beta-naphthylamine and hazardous organic chemicals, which are commonly used in the dye industry and most of these manufacturing industries, are predisposing factors to bladder cancer $[8,9]$.

The World Health Organization (WHO) commends primary preventive checks such as education, risk communication and industrial hygiene practices as the vital steps in the global control of occupational and environmental cancers $[3,10]$. According to the WHO, all countries need to develop communication campaigns tailored to local needs to educate their populations about environmental causes of cancer and prevention strategies. In developing countries, continuous use of outdated technologies and unawareness of the hazards in working places and the environment increase the exposure to carcinogenic agents. Despite achievements in diagnostic tools and the discovery of biomarkers, avoiding or limiting the exposure to these predisposing factors is the most useful approach for preventing occupational cancers [3]. As most cancer deaths occur in low- and middle-income countries, control measures such as screening, training and awareness enhancement programmes can raise a better perspective and cognizance of cancers in these developing countries.

The International Agency for Research on Cancer (IARC) has classified about 150 agents, mixtures and exposure situations as a known or probable human carcinogen [11]. Occupational cancers are not clinically and biologically different from non-occupational cancers. Long latency period and lack of knowledge on the aetiology of bladder cancers among folks lead to late diagnosis and high mortality among patients, especially in Ghana [3]. However, all of them have controllable causes and hence preventable. Therefore, there is a need for comprehensive and structured actions to prevent the causal factors.

\section{Methods}

\subsection{Study site}

The study was a cross-sectional study undertaken at Koforidua and Somanya both in the Eastern region and Kumasi of the Ashanti region in Ghana where questionnaires were answered by local dye workers. The questionnaires were written in English and were anonymous and validated by an epidemiologist. Responders who could not understand English had the questions interpreted in the local language. The urine sample (midstream urine) for the study was solely collected from participants in Kumasi for ease of analysis as there are no laboratories in the other sites. The samples were taken from those who gave consent.

\subsection{Sampling}

The questionnaire for the study was developed based on information drawn from literature and was validated by an epidemiologist and approved by the ethics committee. The questionnaire was in two parts: The first part consisted of background information: age, educational level, nationality and marital status. The second part consisted of knowledge of risk factors and symptoms of bladder cancer and the knowledge of respondents on their occupation in relation to bladder cancer.

Early morning midstream clean catch urine samples were obtained from 40 participants based on the number of years they have been engaged in the tie and dye occupation (preferably 5 years and above), their use of protective equipment and willingness to give urine samples for analysis. The urine samples were kept in sterile urine containers and transported in ice to the histopathology laboratory of the Komfo Anokye Teaching Hospital, Kumasi, where they were immediately tested.

\subsection{Procedure}

The urine samples were thoroughly mixed and centrifuged at $1500 \mathrm{rpm}$ for $15 \mathrm{~min}$. With the supernatant decanted, the sediments were transferred onto a clean labelled frosted glass slide and thin smears were prepared using a spreader (two thin smears for each participant).

The thin smears were immediately fixed using a spray fixative (95\% alcohol) and allowed to air dry before staining.

\subsection{Papanicolaou staining}

The thin smears prepared were stained with Papanicolaou stain using the staining protocol from the Komfo Anokye Teaching Hospital. The stained slides were cleared using xylene and allowed to dry. Prior to the microscopic examination for cancerous cells using a light microscope, the stained slides were mounted using DPX (mixture of distyrene, plasticizer and xylene), airdried and covered with a coverslip.

\subsection{Statistical analysis}

The data were entered into excel sheet and analysed with statistical package for social scientists (IBM SPSS Statistics for Windows, version 25.0. Amonk, NY:IBM Corp. 2017). 


\begin{tabular}{|c|c|c|}
\hline Variable & Frequency & $\%$ \\
\hline \multicolumn{3}{|l|}{ Age (years) } \\
\hline $26-30$ & 56 & 53.3 \\
\hline $31-35$ & 28 & 26.9 \\
\hline $36-40$ & 6 & 5.8 \\
\hline \multicolumn{3}{|l|}{ Religious affiliation } \\
\hline Christianity & 95 & 91.3 \\
\hline Islam & 9 & 8.7 \\
\hline Traditionalists & 0 & 0.0 \\
\hline Others & 0 & 0.0 \\
\hline \multicolumn{3}{|l|}{ Marital status } \\
\hline Married & 53 & 51.0 \\
\hline Single & 43 & 41.3 \\
\hline Separated & 8 & 7.7 \\
\hline Widowed & 0 & 0.0 \\
\hline \multicolumn{3}{|l|}{ Education level } \\
\hline Tertiary education & 1 & 1.0 \\
\hline Senior high school & 9 & 8.7 \\
\hline Junior high school & 52 & 50.0 \\
\hline Primary & 20 & 19.2 \\
\hline Illiterate & 22 & 21.2 \\
\hline \multicolumn{3}{|l|}{ Gender } \\
\hline Male & 95 & 91.3 \\
\hline Female & 9 & 8.7 \\
\hline \multicolumn{3}{|l|}{ Nationality } \\
\hline Ghanaian & 104 & 100 \\
\hline \multicolumn{3}{|l|}{ Monthly income } \\
\hline High & 8 & 7.7 \\
\hline Medium & 48 & 46.1 \\
\hline Low & 64 & 61.5 \\
\hline
\end{tabular}

\section{Results}

\subsection{Socio-demographic characteristics of the study participants}

The socio-demographic characteristics of the study participants are summarized in Table 1. The response rate to the questionnaires was $100 \%$ of the 104 respondents interviewed. The respondents had a mean age of 26.0, with ages ranging from 21 to 40 years, and their age distribution was as follows: $21-25$ years, (13.5\%); 26-30 years, (53.8\%); 31-35 years, (26.9\%) and 36-40 years, (5.8\%). A majority of the respondents (91.3\%)] were Christians, while $8.7 \%$ were Muslims and no traditional religions were recorded. Majority of the respondents (51\%) were married and $41.3 \%$ were single while those who were separated constituted $7.7 \%$ and no widows were recorded. The distribution of education levels showed that $57.7 \%$ of the respondents had junior high school level education or higher [i.e. tertiary education, $1.0 \%$; secondary, $8.7 \%$; and primary, 19.2\%] with 22 participants representing $21.2 \%$ having no formal education. All the participants were Ghanaians. The monthly income of the respondents was grouped into: 100-200 Cedis (low); 201-300 Cedis (medium); and 301-400 Cedis (high) monthly income (Table 1).

\subsection{Awareness levels on bladder cancer}

Most of the respondents $84.6 \%$ were not aware of bladder cancer disease and $16.4 \%$ were aware of the disease. Ninety-eight of the respondents (94.2\%) were not aware that bladder cancer was more prevalent in men. $95.6 \%$ of the respondents were not aware bladder cancer results in severe disease and death, but $4.4 \%$ were aware of the consequences of the disease in men. A minority of the respondents reported receiving bladder cancer information from multiple sources (i.e. mass media, acquaintances and health practitioners).

\subsection{Knowledge levels on bladder cancer}

Consistent with the low levels of awareness, a minority of the respondents (16.4\%) were knowledgeable about the risk factors of bladder cancer (i.e. use of carcinogenic dyes). However, $15.2 \%$ of the respondents were knowledgeable about the signs and symptoms of prostate cancer. Of these respondents, $10.2 \%$ reported difficulty urinating as an early warning sign of bladder cancer. The other signs and symptoms of bladder cancer reported included: blood in urine (8.0\%), abdominal pain (9.0\%).

None of the total respondents were knowledgeable about bladder cancer treatment. Nearly half of the respondents [50 (49.0\%)] reported that bladder cancer was a preventable disease. Rather unfortunately, only $5.0 \%$ of the respondents accepted that regular screening, avoidance of use of carcinogenic dyes and proper diet were frequently reported as preventive measures for bladder cancer (Table 2). Thus, only $16.7 \%$ of the respondents had good knowledge concerning the bladder cancer and a majority (84.3\%) of the respondents had poor knowledge concerning this issue.

\subsection{Perception of self-vulnerability to bladder cancer}

The overall average proportions of the respondent's Likert scores about beliefs on causes, diagnosis, treatment and prevention of bladder cancer were: strongly agree (9.4\%), agree (35.6\%), don't know (3.2\%), disagree (40.9\%) and strongly disagree (10.9\%) (Table 3$)$. In addition, the mean ( \pm standard deviation) of the cumulative Likert scores on the perception scores for beliefs on causes, treatment and prevention of bladder cancer was 
Table 2 Knowledge levels of participants on bladder cancer

\begin{tabular}{|c|c|c|}
\hline Variable & Frequency $(n)$ & $\%$ \\
\hline \multicolumn{3}{|c|}{ Knows the age at-risk of bladder cancer in men and women } \\
\hline$<40$ years & 70 & 67.3 \\
\hline$>40$ years & 25 & 24.0 \\
\hline I don't know & 9 & 8.7 \\
\hline \multicolumn{3}{|c|}{ Knows the signs and symptoms of bladder cancer } \\
\hline Yes & 14 & 13.4 \\
\hline No & 90 & 86.5 \\
\hline \multicolumn{3}{|c|}{ Knows that bladder cancer is treatable } \\
\hline Yes & 30 & 28.8 \\
\hline No & 34 & 32.7 \\
\hline I don't know & 40 & 38.46 \\
\hline \multicolumn{3}{|c|}{ Knows of use of carcinogenic dyes as a risk factor of bladder } \\
\hline \multicolumn{3}{|c|}{ Cancer } \\
\hline Yes & 9 & 8.6 \\
\hline No & 75 & 72.1 \\
\hline I don't know & 20 & 19.2 \\
\hline \multicolumn{3}{|c|}{ Knows that bladder cancer is preventable } \\
\hline Yes & 35 & 33.7 \\
\hline No & 50 & $48 . .1$ \\
\hline I don't know & 19 & 18.2 \\
\hline \multicolumn{3}{|c|}{ Knows of a person suffering from bladder cancer } \\
\hline Yes & 3 & 2.8 \\
\hline No & 101 & 97.2 \\
\hline \multicolumn{3}{|c|}{ Knows that smoking is also a risk factor of bladder cancer } \\
\hline Yes & 20 & 19.2 \\
\hline No & 30 & 28.8 \\
\hline I don't know & 54 & 51.9 \\
\hline
\end{tabular}

Table 3 Perception of participants on self-vulnerability to bladder cancer (BC)

\begin{tabular}{|c|c|c|c|c|c|}
\hline Variable & $\begin{array}{l}\text { Strongly } \\
\text { agree }\end{array}$ & Agree & Don't know & Disagree & $\begin{array}{l}\text { Strongly } \\
\text { disagree }\end{array}$ \\
\hline Respondent believes that they are at a higher risk of getting $B C$ than other men & 10 & 20 & 17 & 32 & 25 \\
\hline Respondent believes that they are likely to get BC in future & 16 & 26 & 11 & 36 & 17 \\
\hline Respondent believes that some people fear dying from BC if they get to know their status & 59 & 21 & 12 & 9 & 3 \\
\hline Respondent believes that there is no prevention of $\mathrm{BC}$ & 40 & 12 & 10 & 37 & 5 \\
\hline Respondent believes that if one already has $B C$, it is too late to get treatment & 12 & 18 & 20 & 39 & 11 \\
\hline Respondent believes that BC kills even if diagnosed early or treated & 21 & 14 & 18 & 23 & 28 \\
\hline Respondent believes that regular checking for $B C$ indicates that one has $B C$ & 27 & 37 & 14 & 16 & 11 \\
\hline
\end{tabular}

34.1 ( \pm 4.4$)$; and the median (range) was 34.0 (18.0-45.0) out of a maximum of 50.0. The mean was therefore used as the cut-off for good (values $\geq$ mean) and poor (values below the mean) perception on self-vulnerability to bladder cancer. Thus, 38 (36.8\%) of the respondents had good perception and $66(63.2 \%)$ of the respondents had poor perception (Table 3).

\subsection{Association between knowledge, socio-demographic characteristics and perception on self-vulnerability of bladder cancer}

Older respondents were found to have poor knowledge as compared to the younger $(p=0.001)$. The proportion of respondents with good knowledge was higher among Christians (58.1\%) as compared to Muslims (5.7\%) $(p=0.094)$. A majority of the respondents with good 
knowledge on bladder cancer had junior high school education (76.7\%) as compared to those having secondary $(40.9 \%)$ and primary $(15.0 \%)$ education $(p<0.0001)$. However, no significant associations were observed between marital status, knowledge levels and income.

\subsection{Uptake, awareness and knowledge of bladder cancer screening}

Of the 104 respondents, all had never been screened for bladder cancer (100.0\%) and none of the respondents were aware of bladder cancer screening or its screening methods. Majority of the respondents accepted to be screened when given the opportunity. Table 4 shows the willingness of participants to take part in bladder cancer screening in relation to their level of knowledge on the disease. Table 5 shows the relation between the sociodemographic variables and the knowledge of participants on bladder cancer.

Pearson's correlation was used to compare knowledge and source of information. There is a strong positive correlation $(r=.3195, p<.001)$ between educated local dye workers and knowledge (awareness) of the use of carcinogenic dyes as a risk factor for bladder cancer. However, the correlation with literature (reading of books) as information source was insignificant $(r=.0111, p<.913)$. A strong positive correlation was found between how easy it is to get information through the mass media (radio, television, etc.) $(r=.4082, p<.001)$ (Table 6). There was also a strong positive correlation between the statement, "dye sellers have talked to me about the use of dye" and health implications $(r=.3195, p<.001)$.

However, there was no significant correlation between the statements, "my friends are knowledgeable" and "I got the information from my friends" $(r=.1204, p<.226)$. There also was no significant correlation between adequate knowledge of bladder cancer and teachers $(r=-.1023, p<.304)$. Only $29(27.8 \%)$ of our participants

Table 4 Knowledge and willingness for uptake of bladder cancer screening

\begin{tabular}{lcr}
\hline Variable & Frequency $(\boldsymbol{n})$ & (\%) \\
\hline $\begin{array}{l}\text { Willing to take up bladder cancer screening when } \\
\text { given the opportunity }\end{array}$ & & \\
Yes & 104 & 100.0 \\
No & 0 & 0.0 \\
I don't know & 0 & 0.0 \\
Willing to know more about bladder cancer & & \\
screening & 98 & 94.2 \\
Yes & 6 & 5.8 \\
No & & \\
\hline
\end{tabular}

Table 5 Socio-demographic characteristics and their level of knowledge regarding bladder cancer among local dye workers (monthly income in Ghanaian Cedis GHS)

\begin{tabular}{|c|c|c|}
\hline Variables & Yes (\%) & No (\%) \\
\hline \multicolumn{3}{|l|}{ Age (years) } \\
\hline $21-25$ & $4(28.6)$ & $10(71.4)$ \\
\hline $26-30$ & $10(17.9)$ & $46(82.1)$ \\
\hline $31-35$ & $8(28.8)$ & $20(71.4)$ \\
\hline $36-40$ & $6(100.0)$ & $0(0.0)$ \\
\hline \multicolumn{3}{|l|}{ Religious affiliation } \\
\hline Christianity & $20(21.1)$ & 75 (78.9) \\
\hline Islam & $3(33.3)$ & $8(66.7)$ \\
\hline \multicolumn{3}{|l|}{ Marital status } \\
\hline Married & $18(33.96)$ & $35(66.04)$ \\
\hline Single & $7(16.3)$ & $36(83.7)$ \\
\hline Separated & $2(25.0)$ & $6(75.0)$ \\
\hline Widowed & $0(0.0)$ & $0(0.0)$ \\
\hline \multicolumn{3}{|l|}{ Education level } \\
\hline Tertiary education & $1(100.0)$ & $0(0.0)$ \\
\hline Senior high school & $3(33.3)$ & $6(66.7)$ \\
\hline Junior high school & $35(67.3)$ & $17(32.7)$ \\
\hline Primary & $3(15.0)$ & $17(85.0)$ \\
\hline Illiterate & $1(4.55)$ & $21(95.45)$ \\
\hline \multicolumn{3}{|l|}{ Gender } \\
\hline Male & $20(21.05)$ & 75 (78.95) \\
\hline Female & $1(11.1)$ & $8(88.9)$ \\
\hline \multicolumn{3}{|l|}{ Monthly income } \\
\hline High & $3(37.5)$ & $5(62.5)$ \\
\hline Medium & $12(25.0)$ & $30(75.0)$ \\
\hline Low & $5(7.8)$ & $59(92.2)$ \\
\hline
\end{tabular}

used some form of personal protective equipment such as gloves, face mask and goggles.

\subsection{Cytomorphology}

Cytomorphological study was carried out among 40 of the participants. The average age of the participant screened was 26 years. Cells identified in most of the

Table 6 Correlation of source of information and knowledge among local dye workers

\begin{tabular}{ll}
\hline Variables correlated (source of information) & $\begin{array}{l}\text { Pearson's } \\
\text { correlation } \\
(\boldsymbol{r})\end{array}$ \\
\hline Mass media & $.4082^{* * *}$ \\
Dye sellers & $.3195^{* * *}$ \\
Friends & .1204 \\
Teachers & .1023 \\
\hline$r=p<.001$ &
\end{tabular}


urine samples include: inflammatory cells, superficial cells, epithelial cells and degenerating cells. Fifteen of the urine samples representing $37.5 \%$ were acellular. No malignant cells were seen in all the samples.

\section{Discussion}

Bladder cancer is one of the leading cancers affecting men in Africa, with an estimated incidence of 40,000 cases and 28,000 deaths in 2008 according to WHO data [12]. Adeloye et al. in 2018 estimated the pooled incidence of bladder cancer in Africa as 7.0 (5.8-8.3) per 100,000 population in men and $1.8(1.2-2.6)$ per 100,000 in women [6]. In Africa, it is most prevalent in Egypt where it constitutes about $30 \%$ of all cancers because of its association with schistosomiasis [13]. In Kenya, there is an increase in the burden of bladder cancer with an approximate incidence of 1087 cases and 889 deaths reported in 2008 [12]. However, the underlying factors that govern this increasing burden of bladder cancer are largely undefined among men in developing countries. Therefore, the current study investigated the awareness and knowledge perceptions on self-vulnerability of local dye workers in Ghana.

Findings from this study indicated very low awareness among the respondents on bladder cancer. This is supported by a study in California where a low awareness of risk factors of bladder cancer was found from the survivors of bladder cancer [14]. However, less than half of the respondents were aware that bladder cancer was a prevalent disease especially in men while at least three quarters of the respondents reported awareness of the serious effects of the disease. Respondents also reported multiple sources of bladder cancer information with the mass media being the leading source of the information. These findings are similar to previous studies among Nigerian men which revealed low awareness of prostate cancer in $80 \%$ of study participants [15]. The mass media was the main source of bladder cancer information in our study. This is supported by a study in India where about $63 \%$ got information about cancer from television [16]. The findings from this study suggest a requisite for improving the quality of information on bladder cancer through delivery of tailored promotion messages via multiple delivery channels including the mass media to capture a wider group of audience.

The overall knowledge levels established in this study are similar to those of Arnold-Reed et al. and Oladimeji et al. that showed very low levels of knowledge on bladder and prostate cancer among Nigerian and Australian men, respectively $[15,17]$. The findings are, however, dissimilar to the studies by Magnus, which showed higher knowledge levels on bladder and prostate cancer of $63 \%$ among African immigrant men living in the USA. This is not surprising since most immigrants had at least high school education [18].

From the study, majority of the participant had incredibly poor knowledge concerning bladder cancer, its causes, risk age and signs and symptoms. This may be explained in part by the poor educational background of most study participants. These findings support a need for concerted efforts aimed at increasing information channels on the disease in the population focusing on its aetiology, signs and symptoms, prevention and treatment modalities. This will ultimately lead to increased knowledge on bladder cancer with increase in early detection and treatment that will reduce morbidity and mortality.

Results from this study also showed most respondents with poor knowledge were older than those with adequate knowledge of bladder cancer. This was consistent with a study among low income minority men and women in South Africa which showed that increasing age was associated with lower knowledge of prostate cancer [19]. While the reasons for these associations are not clear, it is possible that in the current technological age, younger local dye workers are more likely to be educated and more informed about health matters regarding the disease than older men. This is further supported in a study by Ford et al. showing intergenerational differences in health information on bladder cancer. [20]. It is important to emphasize that most of the respondents who had good knowledge on bladder cancer had tertiary or high school level education [16]. The results of this study therefore suggest that education is an important determinant of knowledge on bladder cancer. Religion affiliation in this study appears to have no influence on knowledge levels of bladder cancer.

Overall, only $14 \%$ of the respondents had good perception on self-vulnerability towards bladder cancer. This finding is similar to the lack of awareness of susceptibility to cancers generally in our environment; not just of bladder cancer.

In the study, about $98 \%$ of the respondents were willing to participate in bladder cancer screening and almost $97.2 \%$ of the respondents were willing to learn more about bladder cancer. Thus, having adequate knowledge on bladder cancer is a strong factor for enhancing participation in screening for the disease, which could be achieved through formal and informal education and reinforced through focused health education activations.

None of the urine samples taken for cytology was positive for malignancy. This is probably due to the younger age group of our respondents as the mean age for bladder cancer is in the sixth decade of life $[3,4,11]$. 


\section{Conclusions}

Knowledge on bladder cancer is very low among local dye workers in Ghana. Among local dye workers in Ghana, knowledge and perception levels on self-vulnerability to bladder cancer are influenced by the educational level. The participation of local dye workers in bladder cancer screening is very low; however, most of these workers were willing to partake in the screening and know more about the disease. Therefore there is a direct relationship between education levels, good knowledge on bladder cancer and good perception on self-vulnerability to bladder cancer.

\section{Abbreviations}

WHO: World Health Organization; IARC: The International Agency for Research on Cancer; BC: bladder cancer; USA: United States of America.

\section{Acknowledgements}

We acknowledge the support from staff of the Pathology Department, KNUST.

\section{Authors' contributions}

DA conceptualized the study, collected the data and wrote the first draft. ED supervised and performed cytological staining of the urine smears and contributed to the writing of manuscripts. HN was involved in interpretation and writing of initial draft. DA was involved in staining of cytology slides and data collection. BMD supervised the study, examined and interpreted the urine cytology smears and was a major contributor in writing the manuscript. All authors read and approved the final manuscript.

\section{Funding}

The authors received no external or internal funding for this research.

\section{Availability of data and material}

The excel data used to support the findings of this study may be released upon application to the Committee on Human Research, Publication and Ethics of School of Medical Sciences/Komfo Anokye Teaching Hospital; at Block J, School of Medical Sciences, Kwame Nkrumah University of Science and Technology, Kumasi, Ghana.

\section{Ethical approval and consent to participate}

Approval was obtained from the Committee on Human Research, Publications and Ethics, KNUST School of Medicine and Dentistry and the Research and Development Unit, Komfo Anokye Teaching Hospital (Ref: CHREP/AP/227/17). Verbal consent was obtained from all participants after approval by the IRB.

\section{Consent for publication}

Not applicable.

\section{Competing interests}

The authors declare no conflicts of interest.

\section{Author details}

${ }^{1}$ Department of Pathology, Kwame Nkrumah University of Science and Technology, Kumasi, Ghana. ${ }^{2}$ Department of Medical Laboratory Technology, Kwame Nkrumah University of Science and Technology, Kumasi, Ghana.

Received: 4 June 2020 Accepted: 16 September 2020

Published online: 14 November 2020

\section{References}

1. Sakhvidi MJZ, Aliabadi MM, Sakhvidi FZ, Halvani G, Morowatisharifabad MA, Tezerjani HD et al (2014) Occupational cancer risk perception in Iranian workers. Arch Environ Occup Health 69(3):166-171

2. Wong MCS, Fung FDH, Leung C, Cheung WWL, Goggins WB, Ng CF (2018) The global epidemiology of bladder cancer: a joinpoint regression analysis of its incidence and mortality trends and projection. Sci Rep 8:1129

3. American Cancer Society (2015) Cancer facts and figures. Retrieved from http://oralcancerfoundation.org/wp-content/uploads/2016/03/ Us_Cancer_Facts.pdf on 6th November, 2017 at 05:06 PM

4. World Health Organisation (2014) World cancer report. Retrieved from http://www.who.int/cancer/publications/WRC_2014/en/ on 6th November, 2017 at 05:11 PM

5. Harvard Men's Health Watch (2011) Bladder cancer: men at risk. Retrieved from https://www.health.harvard.edu/mens-health/bladder-cancer-menat-risk on 6th November, 2017 at 05:39

6. Adeloye D, Harhay MO, Ayepola OO, Dos Santos JPR, David RA, Ogunlana $O 0$ et al (2019) Estimate of the incidence of bladder cancer in Africa: a systematic review and Bayesian meta-analysis. Int J Urol 26:102-112

7. Horstmann M, Witthuhn R, Falk M, Stenzl A (2008) Gender-specific differences in bladder cancer: a retrospective analysis. Gender Med 5(4):385-394

8. Bell SM, Scott N, Cross D, Sagar P, Lewis FA, Blaire GE et al (1993) Prognostic value of p53 overexpression and c-Ki-ras gene mutations in colorectal cancer. Gastroenterology 104:57-64

9. Ezzati M, Lopez AD, Rodgers A, Vander Hoorn S, Murray CJ (2002) Selected major risk factors and global and regional burden of disease. Lancet 360:1347-1360

10. Landrigan $\mathrm{PL}$, Espina C, Neira M (2011) Global PREVENTION of environmental and occupational cancer. Environm Health Perspect 119(7):280-281

11. Ferlay J et al. GLOBOCAN 2012v1.0, Cancer incidence and mortality worldwide. IARC Cancer Base No. 11. International Agency for Research on Cancer, Lyon, France. http://globocan.iarc.fr

12. Jemal A, Bray F, Center MM, Ferlay J, Ward E, Forman D (2011) Global cancer statistics. CA Cancer J Clin 61(2):69-90

13. El Mawla NG, El Bolkainy MN, Khaled HM (2001) Bladder cancer in Africa: update. Semin Oncol 28(2):174-178

14. Westhoff E, Maria de Oliveira-Neumayer J, Aben KK, Vrieling A, Kiemeney LA (2016) Low awareness of risk factors among bladder cancer survivors: new evidence and a literature overview. Eur J Cancer 60:136-145

15. Oladimeji O, Bidemi Y, Yetunde A, Oyedunni A (2009) Prostate cancer awareness, knowledge, and screening practices among older men in Oyo State, Nigeria. Int Quart Commun Health Educ 30(3):271-286

16. MahendraS RM, Saini G, Dewesh K, Shikha M (2014) Knowledge, attitude and practices towards cancer among urban dwellers of Jodhpur, Rajasthan. Int J Res Health Sci 2(1):254-262

17. Arnold-Reed DE, Hince DA, Bulsara MK, Ngo H, Eaton M, Wright AR (2008) Knowledge and attitudes of men to prostate cancer. Med J Aust 189(6):312-314

18. Magnus M (2004) Prostate cancer knowledge among multiethnic black men. J Natl Med Assoc 96:650-656

19. Deibert CM, Maliski S, Kwan L, Fink A, Connor SE, Litwin MS (2007) Prostate cancer knowledge among low-income minority men. J Urol 177:1851-1855

20. Ford ME, Vernon SW, Havstad SL, Thomas SA, Davis SD (2006) Factors influencing behavioral intention regarding prostate cancer screening among older African-American men. J Natl Med Assoc 98:505-514

\section{Publisher's Note}

Springer Nature remains neutral with regard to jurisdictional claims in published maps and institutional affiliations. 